\title{
State of the Art: Interlanguage Phonology - Factors and Processes in the Development of a Second Language Phonology
}

\author{
Kevin John Keys \\ Universidade Federal de Minas Gerais
}

O presente artigo visa a resumir as principais questões vinculadas à pesquisa na área de fonologia interlingual, isto é, o desenvolvimento de habilidades fonológicas de uma segunda língua. Os fatores envolvidos neste desenvolvimento são adumbrados e os processos subjacentes são descritos. Os possíveis caminhos para pesquisas futuras são delineados.

[Gileadite challenge to an Ephramite fugitive] 'Art thou an Ephramite?' If he say 'Nay'; then they said unto him, 'Say now "Shibboleth" and he said "Sibboleth": for he could not frame to pronounce it right. Then they took him and slew him at the passages of the Jordan: and there fell at that time of the Ephramites forty and two thousand. Judges, 12:6 (Authorised (King James) Bible, 1612)'

\section{Introduction}

It is fortunately rare nowadays for a pronunciation error to have fatal consequences for the speaker, and although many foreign learners travelling to an English-speaking country have experienced a reaction to their accent which has verged on the homicidal, it seems safe to say that we are moving towards more tolerant and flexible attitudes in relation to the spoken language. The appearance of several works over the past decade have pointed in this direction, which is characterised essentially by the de-centring of the language standards authorities, or in other words, the decline of the importance of the 'native-speaker'. The work of Phillipson (1992), Holliday (1994) and Pennycook (1998) offers a renovated version of the relations between speakers

\footnotetext{
' See also Crystal \& Crystal (2000), 51:9.
} 
of English outside the 'English as an L1' centre and the speakers of English as an L1. Crystal (1997) and McArthur (1998) reveal the extent of the changes that are taking place in the very titles of their books: respectively, English as a Global Language and The English Languages. In terms of the most concrete feature that signifies difference - accent - this tendency culminates logically in the movement towards the concept of 'teaching English as an International Language (TELL), and Jenkins (2000) (The Phonology of English as an International Language) is the most detailed setting out of the principles involved, with reference to phonology, in this area. Her polemic is in relation to the pedagogic failure in ELT to adapt sufficiently to the changing realities of English in the world and to develop methodological paradigms that encompass the new truths about users of English and their needs, and with regard to the outmodedness of most evaluative criteria for teaching pronunciation:

The only really surprising element ... is the relative failure of English Language Teaching (ELT) pedagogy ... to adjust its methodologies in line with this changing patterns, in which the goal of learning is more often to be able to use English as a lingua franca in communication with other 'non-native speakers', i.e. as an international language, than as a foreign language in communication with its 'native speakers'. (Jenkins 2000: 1)

In terms of pedagogic practice, then, this is the background to studies in interlanguage phonology: the relations between L2 speakers of English and the parameters within which these speakers must operate to maintain a sufficiently effective level of mutual intelligibility.

Other concerns that are related to interlanguage phonology studies include topics that are relevant for linguistics in general, that offer insights into the larger processes involved in second language acquisition (SLA) and that raise questions of language development in general from the point of view of affect, cognition and the wider questions of phonological theory. This paper is an attempt to provide an overview of current thinking in interlanguage phonology, and to show its principal tendencies in terms of future research and its connectivity with applied linguistics.

\section{Early concepts of the interlanguage}

The term 'interlanguage' (IL) first arose from the work of Selinker $(1969,1972)$ and referred to the provisional grammars developed by second 
language learners during the process of target language (TL) acquisition. Other terms, such as 'approximative system' (Nemser 1971) and 'transitional competence' (Corder 1967) existed but did not prevail. The term has been unstable in its application, sometimes referring to the acquisition of second languages in general.

The term 'interlanguage' can be seen to apply in two cases: synchronic, or the state of a learner's system at a given point in time; and diachronic, meaning the development of intermediate systems over time. The Il can be seen as a variable point along a continuum between the native language $(\mathrm{NL})$ and the target language (TL), while being distinct from both of these. The $\mathbb{L}$ develops over time as the learner receives input from the TL and modifies the $\mathbb{I}$ according to this information. The idea that the development is linear and progressive is misleading, as at various points in this development the learner may presume that features of the TL take a specific form when in fact the rule (as it were) is applicable only under certain constraints. Or it may be that the input is misinterpreted (either in the light of the NL or in mistaken assumptions about the TL) such that, at that particular point, the $\mathbb{I L}$ presents an unorthodox version of the TL.

Second language learning is characterised by the phenomenon of fossilization, or a state in which the $\mathbb{L}$ has become stabilised and shows no development of specific aspects in the direction of a more TL-like production. This may be the result of various factors, including the communicative success of the learner, when further learning is no longer required given the fact that communication is taking place. Later studies argued that NL/TL similarities (in terms of the overlapping acoustic space for certain phonemes, for example) meant that the learner cannot make the adjustment to a closer approximation because of the dominant influence of the NL rules. Fossilization does not occur in first language acquisition (FLA), which is therefore seen to be a different cognitive process from that of $\mathrm{L} 2$ acquisition.

\section{IL as rulle-govermed behaviour}

Adjemian (1976) argued that IL was a set of systematically developed rules, an argument that was reinforced by Dickerson's (1974) study of Japanese learners of English (see below). Adjemian stated that the IL grammar was susceptible to linguistic analysis in the same way as any natural language, obeying universal linguistic constraints and showing internal consistency. To investigate this, Adjemian suggested that research look at the intermediate 
states of a learner's developing IL to see what underlying rules were governing the variable production at different stages. Analysis of learner production then became not a question of error analysis but of variability analysis, requiring the study of large amounts of data that might throw up the regularities inherent in the $\mathrm{L}$ of a given learner of language $A$ when learning language $B$. The context is significant, since the problems involved in the move along the continuum from $\mathrm{A}$ to $\mathrm{B}$ will be conditioned by the linguistic relations existing between these two languages. That is, for example, the forms of 'transfer' that may occur will depend on the existence, or otherwise, of comparable, or competing, features in the two languages. Word order rules from German, say, may be retained in learners acquiring English because English allows for apparent order flexibility (even though violating grammatical rules), whereas the inclusion of particle markers ( $a$ in Japanese for example) is unlikely to occur between languages where the TL has no mechanism for such a procedure to manifest itself (Adjemian, op.cit. passim).

\section{A third approach}

Tarone (1979) sees the $\mathbb{L}$ as a set of styles that are dependent on context of use. The research shows that the systematic variability of IL usage is related to (1) the linguistic context and (2) the nature of the task involved for elicitation purposes. Tarone related variability to the attention the learner pays to production: she identified a stable subordinate style free of L1 influence which was on a continuum with a superordinate style which reflected greater attention to production and thence demonstrated greater LI influence, probably because of a decrease in automaticity. The question here is one of monitoring, in the Krashen (1977) model: the greater the degree of monitoring (or conscious attention to the structure of the language) the higher the likelihood that the learner would revert to linguistic knowledge based on the NL, all of which is automatised, at the expense of non-automatic knowledge - or awareness - of the TL.

In using the TL, the learner will prefer a style somewhere between the formal and the vernacular and will use a range of categorical and variable rules that reflect this choice. As the learner style shifts to paying more attention to language form, some categorical rules may become more variable and some variable rules more categorical as they are increasingly influenced by the TL. 
Both Tarone and Adjemian assumed that the $\mathrm{IL}$ is a natural language, with the same universal constraints and subject to linguistic analysis in the standard way. Tarone added the sociolinguistic aspect to Adjemian's version, arguing that the $\mathrm{IL}$ is a set of systems that changes according to the social context of the speech event. Thus, Tarone's position is similar to Selinker's in so far as it presupposes a set of flexible rules that are dynamically variable.

\section{Descriptive studies}

Interlanguage studies in the 1970s were confronting the prevailing views on second language learning, which were psychologically behaviourist and linguistically structural. Research into IL grammars, and the assertion that ILs were natural languages repudiated the behaviourist emphasis on external factors. The behaviourist position was one that saw transfer as fundamental to the development of IL: old habits interfered with new habits. New research showed that interference had a less significant role in this process.

The Contrastive Analysis Hypothesis $(\mathrm{CAH})$ was aimed at predicting, on the basis of a linguistic comparison of the grammars of the languages in question, what would be easy and what difficult in the acquisition of language A by a speaker of language $\mathrm{B}$. The $\mathrm{CAH}$ was shown to be fallible in this strong form because it overpredicted, anticipating problems where none could be shown; and underpredicted, by failing to explain learner errors that could not be seen as the result of transfer between languages. These conclusions were drawn from morpheme studies and error analysis.

\section{Morpheme studies and error analysis}

Morpheme studies showed that children L2 learners seem to acquire language in similar stages, regardless of their exposure or their L1. This pattern was shown in adult learners too. Error analysis of learners' production showed that the main influence on production was the TL and not the NL children were evidencing developmental errors rather than transfer errors. Developmental errors are those that are similar in kind to the errors made by native learners of the TL, i.e. monolingual speakers learning their own language. The similarities seen in the morpheme studies across learners from different language backgrounds and the predominance of developmental errors over interference errors led to the view that $\mathrm{L} 2$ learning was similar to $\mathrm{L} 1$ 
acquisition in that both processes involved possibly universal linguistic operations.

These conclusions were challenged in the late 1970s. Morpheme studies of a more exacting kind found in L2 learners the kind of orders of acquisition that were characteristic of $\mathrm{L} 2$ learning, rather than being similar to L1 acquisition. Morpheme studies did not reflect an acquisition sequence but rather the accuracy of use, because they measure usage in elicited contexts. Longitudinal studies - of which there are too few in the whole range of research in second language acquisition - demonstrated other orders of acquisition which were not correlated with accuracy of use.

Error analysis was challenged because of the difficulty in identifying the nature of an error or the reason why it is made. (Schachter and CelceMurcia 1977). The same error can be assigned to intralingual factors (paralleling developmental mistakes made in FLA) and to interlingual factors which reflect the influence of the L1. Some errors may be the result of the interaction of both these factors. Another problem with error analysis studies is their cross-sectional nature: they look at heterogeneous groups of subjects synchronically, rather than gathering data from a small groups of subjects at different moments in their acquisition. Longitudinal studies would show what kind of errors appear at what times and which are more likely to persist and for how long. This would indicate more precisely the dynamic nature of the underlying IL grammar(s) and may lead to insights about how developmental errors come to predominate over transfer errors, as in the ontogenetic model of acquisition described by Major (1987). This model (to be looked at in detail below) sees the increase in knowledge of the TL as having a gradually growing effect on the interpretation of new information by the learner through exposure to the TL, and thus sees 'transfer' as something that can occur at both ends of the NL - TL continuum.

What was needed was research into the dynamic qualities of language change that made the IL a unique (and flexible) system, both similar and different to the NL and the TL.

\section{Recent developments in IL theory}

Current interest in IL theory is focused on questions of how systematic the $\mathrm{IL}$ is and how variable; how ILs are acquired; and what the role is of the NL. 
$\mathrm{L}$ systems are by their nature dynamic and changeable. However, research has focused on the product at given moments in the acquisition of the TL. The need for studies which reflected this fact was felt and is still relevant today. The Contrastive Analysis Hypothesis in its weak form is being used to understand the nature of learner production at given points in the acquisition process to see how each learner demonstrates patterns of linguistic behaviour that are common to learners of a TL who have a NL in common. It is by basing research on actual language of learners and creating a database of information on the parallel experiences of these learners that will lead to a better understanding of the process involved in SLA and the effect of both the NL and the TL on the dynamics of the $\mathrm{L}$ at various stages in language learning.

\section{The role of the first language}

The Il is systematic and therefore can be explored as a dynamic phenomenon: research showed difference within individuals (as competence fluctuated while the learner distinguished various form-function operations) and between subjects (because of their different L1s). How does the L1 influence the IL?

The fact that a form occurs in both NL and TL is no guarantee that transfer will take place. Product-oriented analysis is therefore insufficient as a research methodology. Speakers of Finnish, Japanese and German L1s have been shown to acquire functions at the same rate (Keller-Cohen 1979); however, the acquisition of yes/no questions was slower in the Finnish speaker, because of a difference in L1/L2 structures. Thus, the result was the same but the process was different because of $\mathrm{L} 1$ differences.

That developmental processes are different because of L1/L2 differences is evidenced by the fact that speakers of some NLs take longer to acquire control over certain forms than speakers of other NLs because their NL have similar forms - that is, similarity to the NL delays the acquisition process. Schumann (1979) showed that no + verb forms are more difficult to eliminate from the $\mathrm{IL}$ of Spanish speakers than form the ILs of other speakers because this pattern exists in Spanish. 


\section{Interlanguage phonology and language transfer The Phonology of Interlanguage: processes and constraints}

Tarone (1987) explains that in earlier studies, the question of the influence of the L1 on L2 acquisition of phonological skills was considered paramount and a contrastive analysis between the L1 and the L2 would be sufficient to predict and hence avoid errors during acquisition. The problem for the learner was the simple one of using native language (NL) sounds when producing the target language (TL), or negative transfer. This can be exemplified in the following table:

Table 1

\begin{tabular}{|c|c|c|}
\hline & $\begin{array}{l}\text { native } \\
\text { language }\end{array}$ & $\begin{array}{l}\text { target } \\
\text { language }\end{array}$ \\
\hline (1) & $\mid t /$ & $/ t^{\prime}$ \\
\hline (2) & $/ \mathbf{f} / 1$ & $/ \mathrm{f} /$ \\
\hline & $\mid \mathrm{v} /]$ & - \\
\hline (3) & $n /$ & $\begin{array}{l}h / \\
/ \mathrm{r} /\end{array}$ \\
\hline
\end{tabular}

From Tarone (1987:71)

In (1) we have the potential for positive transfer, since both languages include the phoneme $/ t /$ in their inventories, leading us to expect that learners would have no trouble in producing that sound in the target language.

In (2), we have what might be termed convergent negative transfer: where the $\mathrm{L} 1$ has two phonemes, /f/ and $/ \mathrm{v} /$, the target language regards these as allophonic variations of /f/. An allophone is a variation in the pronunciation of a sound that does not affect the meaning of a word: for example the first sound in pit can be aspirated or not and the use of the aspirated or the non-aspirated variation makes no difference to the meaning. So, the situation in (2) is that in one language the difference is important and in the other it is not; but for the learner, the two sounds exist and are easy to transfer from one to the other.

The example in (3) is more difficult and may be described as divergent negative transfer. This might cause more difficulties for learners, since where their L1 has only one phoneme $/ \mathrm{l} /$, the target language has two, $/ \mathrm{h} / \mathrm{and} / \mathrm{r} /$. This asymmetry gives rise, for example, to the commonly-recognised tendency 
of $/ \mathrm{I} /$ for $/ \mathrm{r} /$ substitution by Japanese $\mathrm{L} 1$ speakers learning English (giving [laiz] for /xarz/ $<$ rise $>$ ). These are therefore likely to be interpreted as allophones by the learner, when in fact they represent distinctive features and make a difference to the meaning of what is said.

Further research in this area has showed that contrastive analysis is not sufficient for predicting learner performance on specific tasks of L2 production. In the first place, tests on the production of isolated phonemes are not subtle enough to take into account the influence of suprasegmental features on oral production. For example, in an analysis of speakers of English as an L1 learning Arabic, it became apparent that the distribution of the phoneme in the syllable affected learners' ability to control the sound in other syllable positions (Brière 1966, in Tarone 1987).

Further studies reported by Tarone showed that perception was a crucial factor in influencing learners' output. Contrastive analysis was not able to predict with any accuracy learners' errors in the L1 - L2 confrontation.

None of the research reviewed by Tarone utilized spontaneous speech as data: the tasks were mainly focused on perception and concentrated on words and sounds in isolation. This ignored the fact that interlanguage phonology (ILP) is sensitive to context: the communicative situation (the topic, the interlocutor relations, the degree of formality) has a fundamental effect on the kind of speech production that subjects demonstrate and therefore research should be based on spontaneous speech data.

On the other hand, White (1989) argues that there is a tendency for learners to use avoidance tactics for certain structures, so we need to discover whether learners are avoiding certain phonemes because they don't like them and not failing to produce them because they cannot, not having acquired them yet. The implication of this is that research must at some point employ tasks that are designed to elicit specific phonemes from the subjects that they may otherwise not use for fear of their lack of competence. A combination of spontaneous speaking tasks and directed elicitation tasks are therefore required if the research is to generate data that is broad enough based to be relevant.

Dickerson's (1974) study of a Japanese speaker showed that progress is measured by increasing approximation of the ILP variants to L1 norms in their respective linguistic environment. The ILP is essentially a variable system: it varies over time, as control over the TL phonology improves with practice; and it varies synchronically, depending on the nature of the task imposed on the speaker. Dickerson noted that non-linguistic constraints operated on the 
output of the interlanguage phonology. Proficiency was seen to be higher in word list reading than in dialogue reading, which in turn was better than free speech (see Tarone 1987:77). Being aware of this variability is essential if we are to understand the processes involved in developing an interlanguage phonological system: negative transfer from the Ll, developmental processes that are intrinsic to the L1, over-generalization, approximation and the inherent difficulty of the TL phoneme inventory.

At the level of the syllable, Tarone's own research concludes that (following Dickerson) favourable phonological environments may be due to transfer effects (the existence of similar environments in the NL) or to universal effects, such as the fact that there may exist a universal physiological constraint whereby the articulators tend towards the rest position. For transfer effects to operate at the level of the syllable, we would expect to see the syllable structure of the NL transferred to the TL, so NLs with VC-type syllable structures would tend to reduce TL syllables to a similar VC form. A further aspect of this process would be the reactivation of L1 learning processes: the simplification of syllables that occurs in L1 acquisition would be repeated during $\mathrm{L} 2$ learning.

However, as Oller's (1974) research demonstrated, L1 and L2 processes are unalike. Young learners of L1 English will use strategies such as cluster reduction, final consonant deletion and weak syllable deletion (aphesis). On the other hand, L2 learners will use epenthesis rather than either cluster reduction (tree $\rightarrow$ [tori:] rather than [ti:]) or final consonant deletion (big $\rightarrow$ [bigu] rather than [bI]), and will tend not to show weak syllable deletion. Epenthesis is favoured by L 2 leamers, where deletion is used by L1 learners. This deletion could be a question of transfer, but Tarone prefers a universal feature hypothesis which states that the CV syllable may be 'a universal articulatory and perceptual unit such that the articulators tend to operate in basic CV programs in all languages' (Tarone 1987:78). This hypothesis found some limited support in Benson's (1988) paper, which emphasised the importance of vocalic context, stating that 'universal preference for an open syllable does play a role, albeit minor, in shaping $I L$ phonology independent of the process of NL transfer.' (Benson 1988:232).

The question of avoidance is also crucial to the development of interlanguage phonologies. Celce-Murcia's (1977) observations of a child learner showed that the learner had a preference for sounds that were easier between the two languages to which she was simultaneously exposed. This learner of English and French would had problems with fricative sounds and 
showed a preference for couteau over knife irrespective of which code was in use at the time (Tarone, 1987:79). Thus physiological constraints (the relative physical difficulty of producing certain sounds) provoked a learning strategy of avoidance to shape the interlanguage phonology.

With reference to prosodic features, Tarone again acknowledges that more than just transfer processes are involved. Backman's (1977) study of Spanish speakers learning English analysed the errors in intonation (error which made up $78 \%$ of their oral production) and found that the features which characterised the errors (smaller pitch range, a higher pitch for unstressed syllables, for example) were not attributable to transfer effects.

To summarize, Tarone's (1987) review of the current knowledge in interlanguage phonology identified the following processes and constraints as operating in the development of L2 ILPs:

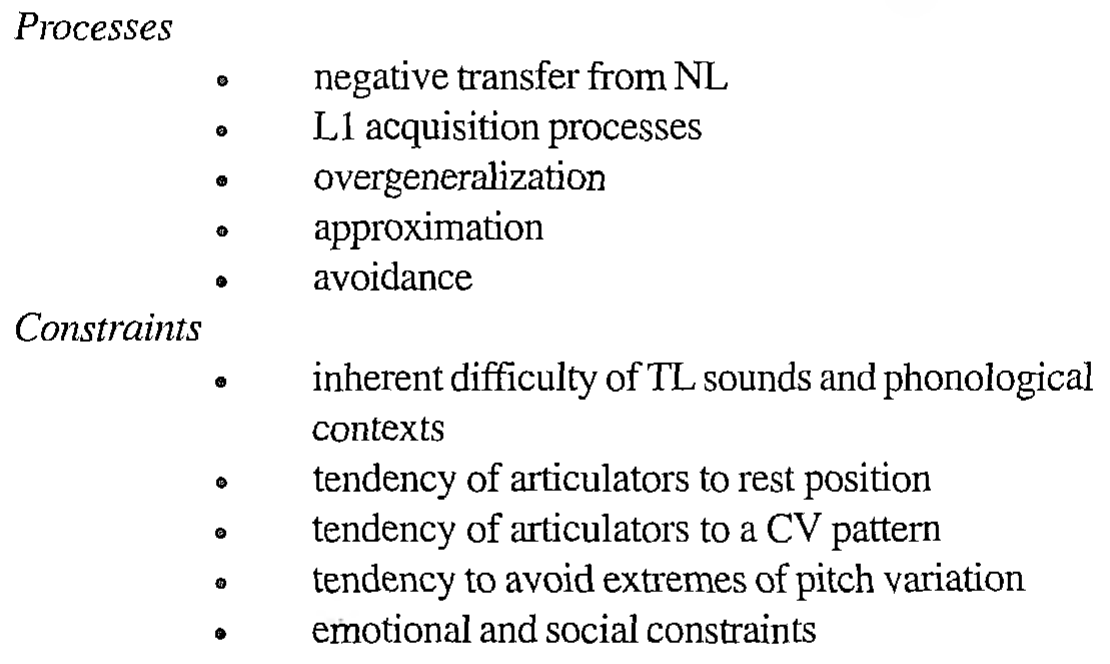

(Tarone 1987:79)

\section{Fossilization}

The other key issue that Tarone identifies as relevant for ILP studies is that of fossilization. The questions are whether fossilization is inevitable in the process of $\mathrm{L} 2$ acquisition; and what are the causes of fossilization?

Fossilization should additionally be seen as deriving from cultural factors. Resistance to adopting the full phonemic range of features in the TL may be related to questions of identity and personal image, which are questions 
of Western culture. In other cultural contexts, the achievement of native-like fluency amongst learners who began to study the TL after puberty is common. Hill's (1970) study of peoples in the Amazon and in New Guinea found adults who achieved native-like pronunciation competence in several $\mathrm{L} 2 \mathrm{~s}$. These findings have not been confirmed.

Tarone maintains that it is not possible to analyse the relative effects of language transfer on pronunciation as compared with syntax and lexis (Tarone, 1987:81). Fossilization may be a matter of psychological habit formation which, combined with language transfer, make the interlanguage phonology resistant to change.

Continuing with the cultural influence on L2 acquisition criteria, fossilization may be associated with an essential lack of empathy with the TL and the TL culture. This, together with emotional and affective constraints, may lead to acquisition reaching a certain point and not progressing further. Adults have more rigid language "ego boundaries" and use their accent to identify themselves appropriately. A challenge to this accent is a challenge to the individual's identity and hence is resisted by some learners. However, socio-emotional factors are hard to measure under research conditions or in experimental settings.

\section{The Ontogenetic Model}

Major's (1987) study presents a simple model for interlanguage phonology that takes into consideration the factors dealt with by Tarone (1987) and the critical period hypothesis. What we have been calling language transfer, Major knows as 'interference' ${ }^{2}$ and recognises its low predictive power. His ontogenetic model is designed to compensate for the fact that L2 phonological studies (up to that point) had focused on error sources but without paying attention to the reasons for stages of acquisition. This model attempts to articulate the relationship between interference and developmental factors.

Major's basic premise is that interference processes affect early stages of acquisition and decrease with time, while developmental processes begin as infrequent, increase in frequency over time and then fall away. This is an

\footnotetext{
2 'Interference' is a term that has been largely abandoned in the literature because of its negative connotations and the implication that all transfer is inevitably a bad thing. (See Gass \& Selinker, 1983/94:15n and Corder 1983:19.)
} 
abstract account, not based on numerical data. Individual differences in the time period and the crossover point will vary. Fossilization may occur at any stage. Major describes his model thus:

At an early stage of acquisition, interference processes dominate at the expense of developmental processes. As acquisition proceeds, interference processes give way to developmental processes, which gradually increase and then decrease over time. (Major, 1987:103)

At early stages, interference processes prevent developmental processes from operating. As interference diminishes, then developmental processes can begin to appear.

An example would be for a speaker of Brazilian Portuguese (BP) learning English. At beginning stages, these learners evidence paragoge after voiced stops ([dpgi] for [dog]), which represents interference from BP, where syllable structure is generally $\mathrm{CV}$. At a later stage, the [i] is replaced by [ə]. The developmental process that might operate here - terminal obstruent devoicing - cannot because of the paragoge. Major claims that the stages of acquisition can be characterised as follows:

[dogi] (interference) $\rightarrow[$ dogə] (developmental) $\rightarrow[$ dok] (developmental) $\rightarrow[$ dog]

However, it is not clear why the first change (from [dpgi] $\rightarrow$ [doge] should be seen as developmental, unless it is being claimed that L1 learners of English manifest this process, which we doubt. Furthermore, the third stage ([dok]) is also what we consider to be potential rather than actual in the production of Brazilian speakers learning English (although this is a hypothesis that remains to be tested).

According to this model, then, a beginning learner will transfer NL forms on to the TL because too little of the TL has been learned; as the $\mathrm{IL}$ system is modified by contact with the TL, it (the interlanguage) will show "new cognitive structures" which will again affect the developing $\mathbb{I L}$. The $\mathrm{TL}$ has its unique developmental features and as the TL is increasingly influential over the $\mathrm{I}$, so these developmental processes will begin to appear. The $\Pi$ becomes more like the TL and so substitutions will follow from the TL system rather than from the NL (Major, 1987:104).

A simple example of this process in operation can be seen in the phenomenon of overgeneralisation, which is by definition a TL-influenced 
effect, as the generalisations are based on incomplete knowledge of the TL and the overgeneralizations are therefore influenced by incomplete knowledge of the TL, not by interference from the NL, which may not have any of the features being generalised in its morpho-syntactic or phonological repertoire.

Major also proposes that this relationship between interference and developmental factors is also relevant for stylistic shifts. As style becomes increasingly formal, interference decreases and developmental factors increase and then decrease. This echoes Dickerson's (1977) finding that free speech is less proficient than dialogue reading, which is less proficient than word list reading (see page 8 above). Major's own research into testing this model was inconclusive and it remains a suggestion only of the kind of schematic relationship that might exist between these two elements, interference (preferably, 'negative transfer') and developmental processes.

\section{Language transfer: definitions and processes Corder (1983) and 'the role of the mother tongue'}

Corder's (1983) article was contextualised by his comments on current thinking on language acquisition under the then new 'shift in emphasis' he identified as taking place in SLA studies. This shift in emphasis was the move to 'communicative approaches' to language teaching, which he saw as essentially a move from a concern with formal properties of language to a focus on function, with more emphasis on communicative fluency rather than grammatical accuracy. This was associated, he stated, with a change in the framework for SLA research, which was now cognitive in nature, seeing language acquisition as the creation of a body of knowledge which produces utterances in the TL.

The complexity of this process is represented in the learner's interlanguage, which Corder describes as 'an internalised representation of the regularities [learners] discover in the linguistic data to which they are exposed' (Corder, 1983:20). The question that research has been focusing on is related to the nature of the development of this interlanguage and how dependent it is on the kind of input that is available to the learner. That is, of the two types of input that are generally available - teaching syllabuses and the occurrence of forms in normal exposure to the TL - which is more helpful to the learner? Current research at that time suggested that developmental sequences were independent of teaching input (Corder cites no source for this position), and Corder suggests that there may be an 'internal program' 
that the learner uses to create 'essentially the same sequence of development of the internal representation so long as there is adequate data for the acquisition process to operate on.

Given this unchanging developmental process and its independence from the external processes such as teaching input or variation in the data (available to learners), the question is what can be stated with regard to internal processes? For Corder, these include affective factors such as motivation and attitude; but primarily, the knowledge the learner has of another language, the L1. While affective factors will probably not influence developmental processes (but only developmental rates), the cognitive fact of the presence of the L1 'might reasonably be expected' to influence the order of the developmental process.

For Corder, similarity between $\mathrm{L} 1$ and $\mathrm{L} 2$ potentiates the facilitative function of the L1 in the acquisition of the TL. The Ll, he claims, has a heuristic role in this process: by this is meant, presumably, that the L1 helps in the process of discovering how the TL functions, by means of experimenting with L1 elements in L2 contexts and seeing how successful (communicatively) these are. Therefore, as a logical consequence, the greater the 'distance' between the $\mathrm{L} 1$ and the L2, the fewer possibilities there will be for this heuristic process to operate: the learner becomes aware of the extent of the differences between the two languages and gives up the attempt to use $L 1$ features in a straightforward one-to-one mapping of lexical items on to, say the syntax of the L2 (a process described as 're-lexification' by Zobl (1980). Corder describes this as the learner discovering the relative 'borrowability' that is possible between two languages and discusses this further later in his text.

One of the problems Corder identifies in SLA studies is the assumption that language learning is a linear, cumulative process (Corder, 1983:21). This belief is reflected in the syllabuses that are used for teaching, with their ordered lists of structural items that are apparently organised into a hierarchy of relative difficulty, a hierarchy that is also chronological (some structures are to be learnt before others, and so on). This organisational convenience has an effect on perceptions of language acquisition as linear progression.

Corder's metaphor is of knowledge of language as 'an organically structured whole'. The structure, over time, develops from simple to complex but not in ways that can be seen linear. His analogy is with a flower bud developing into a bloom, where all parts of the structure are developing simultaneously (and nothing is complete until the whole is complete). Given this analogy, it is difficult to see how 'transfer', as a notion of structural exchange, could operate. 
Corder's position here is that (a) language knowledge is a matter of internal representations of the TL based on information from that language in use and (b) the process of the development of that language knowledge takes place on multiple fronts, in a simultaneous and interdependent organic way. This means that (c) 'transfer' cannot operate at the level of structure, but may function as a way of testing the possibilities for the use of $L 1$ features in the L2, depending on how 'similar' the L2 is perceived to be by the learner. Corder calls this 'borrowing' from the $\mathrm{L} 1$ into the $\mathrm{L} 2$ and sees it as a possible mechanism for structural transfer, at later stages of acquisition.

\section{Interlanguage}

Corder also thinks of language acquisition as occurring along a continuum whose ideal terminal point is knowledge of the TL (although he is careful not to stipulate if that knowledge is 'native-like' or not). In historical linguistics, this continuum represents the changing nature of a language over time, with lexis and syntax being adjusted according to whatever forces act upon a language at any given moment. As Corder states, rules may change, be added to or lost: the overall complexity of the language is neither diminished nor increased. The interlanguage continuum, on the other hand, is presumed to start at a point of maximum simplicity in terms of the TL but with the complexity of the $\mathrm{L} 1$ as an underlying theme. For Corder, this is problematic: some interlanguage proponents argue that the starting point of the interlanguage is the $\mathrm{Ll}$, which is then restructured during acquisition through 'a sequence of approximative systems progressively more similar to the target language' (Corder, 1983:23). This model would mean that the interlanguage is more L1-like at earlier stages rather than later.

For Corder, such a model would mean that the learner's early utterances would be more L1-like than target-like. However, research cited by him (Ervin-Tripp, 1974) shows that early L2 production is pidgin-like in its syntax and is not influenced by the L1. The continuum in SLA is therefore one of increasing relative complexity rather than readjustment with an underlying isobar of linguistic richness. It is a developmental continuum rather than a restructuring continuum, similar to those found in the postpidgin forms that become creoles, or the first language acquisition (FLA) continuum of development. He argues that the starting point of the SLA continuum cannot be the L1, or the initial production of L2 learners would not be pidgin-like in its simplicity. 
It is this question of the starting point for the $\mathrm{L} 2$ continuum that is significant here. The learner of an L2 already has a language and the experience of learning a language. The $\mathrm{L} 2$ learner's initial production is very pidgin-like and Corder suggests that the L2 learner has 'regressed to an earlier stage of his own linguistic development' - that is, has returned to a stage in linguistic terms that predates the first stages of development of the $\mathrm{L} 1$. He also speculates that this earlier stage is so stripped down grammatically speaking that it may reflect a basic, universal grammar that is available to all learners regardless of their specific $L 1$.

Corder also rejects the suggestion that what the learner works with at the initial stages of acquisition is some sort of simplified version of the TL, as, logically speaking, you cannot simplify the knowledge of a system if you do not yet have that knowledge (Corder cites Valdman (1977) in support of this).

\section{'Borrowing'}

The role of the mother tongue for Corder then is that of a heuristic and facilitative resource that is available to learners after the initial stages of acquisition and is used by them to '[help] in the process of discovery and creation' (Corder, 1983:25). He has rejected the concept of 'interference' by showing that language dissimilarity implies a reduction in the possibility for using the L1 as a resource for filling in knowledge gaps in the L2. The L1 is potentially helpful for discovering features of the L2; it is not demonstrably inhibiting to language development: there is no 'proactive inhibition of facilitation', in Corder's words (Corder, 1983:21).

Corder has strong doubts about whether transfer also occurs. Avoidance features, which are so characteristic of some learners' L2 production, cannot be said to be derived from 'transfer' processes. If there is transfer, it must be at a higher level of cognitive complexity:

if anything which can be appropriately called transfer occurs, it is from the mental structure which is the implicit knowledge of the mother tongue to the separate and independently developing knowledge of the target language. (Corder, 1983: 25)

Some evidence for this process would be the persistence of errors in learner's production that were L1-like, in other words what Schachter (1978) 
called 'resident errors' and what Selinker (1972) tagged as 'fossilization'. Corder argues that there may be another explanation for this process altogether, what he calls 'borrowing'. The fact that borrowing phenomena are highly variable and situation-dependent means that they have to be a performance phenomenon rather than the result of cognitive necessity.

Corder explains the function of borrowing in his sense of the term as a communicative strategy that leads to 'success' that is defined by the ability to communicate (rather than from the point of view of grammaticality). Borrowing between fairly similar languages has a reasonable degree of success in this sense of the term, with no consequent pressure existing to lead the learner to more grammatically accurate forms of production. Hence, ungrammatical forms that have been generally successful communicatively speaking will tend to persist in the performance of the learner. Formal instruction, Corder reminds us (citing Krashen, 1981), can have little effect on error production and so it is as justifiable to claim that persistent error is as likely to come from borrowing as it is from structural transfer.

In fact, as Corder goes on to claim, borrowing may be the mechanism whereby transfer of structures takes place, as successfully borrowed items are gradually absorbed into the interlanguage grammar:

It is only after regular, repeated and communicatively successful use of the borrowed items that they come to be incorporated into the language system of the borrower's mother tongue. (Corder, 1983:28).

This successful use provides, in fact, both mechanism and motivation for structural transfer: the mechanism is the speculative borrowing that closely similar languages encourage; the motivation is that this borrowing strategy is frequently communicatively successful in those situations.

\section{Language transfer: fundamental problems}

Odlin's (1989) work on language transfer begins by outlining some of the problems inherent in the study of this phenomenon, including problems of definition, comparison and prediction.

\section{Definition}

Language is vague and unspecific; definitions are never complete or wholly satisfactory, either for semantic (connotations, polysemy) or for 
ideological reasons. The term 'applied linguistics' itself is ill-defined and the domain is open to include a superfluity of (sometimes conflicting) intellectual interests. The term 'transfer' is no exception; Corder, as we have seen, seemed to advocate abandoning the term altogether (Corder, 1983:21). One way around this problem is to define what transfer is not, to leave a clearer idea of what is contemplated in the terminology.

It is also necessary to consider the term transfer and its relation with the idea of 'interference', a term which was itself rejected by Corder. Odlin's position is that the influence of the native language is positive and helpful ('facilitative' in Corder's formulation) rather than not. The preferred term here is negative transfer, as this indicates the possibility of the main tendency, positive transfer, and all this can be seen as a way of explaining the effect of, for example, false and true cognates in the lexis of the two languages: false cognates (to pretend and pretender in English and Portuguese respectively) may lead to negative transfer and true cognates (to pronounce and pronunciar) to positive transfer.

Moreover, it is not always the case that transfer processes indicate a reversion to the L1, as was claimed by Krashen (1985), where applying an L1 rule in an L2 context was seen as a consequence of a lack of knowledge of the L2 rule. For Odlin, this position ignores the advantages that are implicit in the possession of a previous language (or languages) by the learner who is beginning to learn an additional idiom. The interaction between the language is not always manifested in rule-based behaviour: cross-linguistic benefits can be seen at levels of orthography, for example, or in the long-term results of language contact in some cultural settings.

In many learners, the distinction L1 and L2 is shorthand for a situation where other languages and dialects may be involved. Transfer, then, may not always come from L1 sources. As Corder shows, other languages in development in the learner may help in the acquisition of a further language, and may even be preferred by the learner to the L1 (Corder, 1983:25).

This leads us to look at the two types of transfer that Odlin distinguishes and which has links to Corder's notion of (perceived) 'borrowability': borrowing transfer and substratum transfer. The first of these, borrowing transfer, refers to the influence that is sometimes felt on a previously learned language by a language that is the process of being acquired: the L2 may have an effect on the L1 of the learner. Substratum transfer is the focus of this study and refers to cross-linguistic from the L1 to the L2. Odlin's definition of substratum transfer is as follows: 
Transfer is the influence resulting from similarities and differences between the target language and any other language that has been previously (and perhaps imperfectly) acquired. (Odlin, 1989:27).

This is only a tentative approach to a definition and all the terms invoked here would need to be examined carefully before an adequate determination of what transfer might be can be outlined.

\section{Comparison}

The study of transfer depends on systematic comparisons of the languages involved. Structural factors are fundamental to these comparisons but they are not sufficient: some awareness of non-structural factors has to be available (Odlin, 1989:28). In addition, descriptions need to be augmented with theoretical principles which allow for useful predictions to be made about what will be difficult or easy in the study of language $B$ by speakers of language A. Descriptive accuracy is essential for a theoretically adequate grammar to exist; no language has yet been completely described so this precondition for theoretical accuracy is unfulfilled.

A key question in comparative studies lies behind the earlier assumptions (Lado, 1957; Fries, 1945) that equated difference and difficulty. More subtle analyses have been required to understand what difference may mean. For example, where a structural feature in one language has two counterparts in the target language, the degree of difficulty may be increased, but asymmetrically. That is, the verb to be in English has two counterparts in Portuguese (ser and estar). This feature causes problems for English speakers learning Portuguese, but not for Portuguese speakers learning English.

\section{Prediction}

Odlin identifies two types of prediction: that based on records of past events (French learners of Arabic in the past have left performance data about the problems of learning Arabic) and that based on cross-linguistic comparisons. The latter type would require predictions to be made before learners actually began to learn the language and their performance could be studied. This means that the comparison of the languages in question would have explanatory power, explaining why transfer will or wilt not take place under certain conditions. 
The classification of outcomes of cross-linguistic influence that Odlin presents are:
I.Positive transfer
II.Negative transfer
a. underproduction
b. overproduction
c. production errors
d. misinterpretation

III. Differing lengths of acquisition

(Odlin, 1989:36)

Positive transfer can be seen in a reduction in vocabulary acquisition time for languages with a similar lexicon; ease of acquisition of vowel systems where these systems are alike; the facilitating effect of comparable writing systems; syntactic similarities (word order, articles, relative clauses) help with the acquisition of grammar. An evaluative measure of ease or difficulty can only be done by comparing speakers of different L1s learning the same L2.

Negative transfer means divergence from target language norms. These divergences are not necessarily to be defined in terms of production. Underproduction means that some TL structures rarely appear in learners' performance. Another term for underproduction is avoidance, where learners will tend not to produce structures that they perceive to be very different from their L1 versions. Overproduction may be a consequence of this: by avoiding certain structures, learners come to depend on a limited range of alternatives which then appear in their production more frequently than for a native speaker.

Production errors include

substitutions, where an L1 word is used instead of a TL item;

calques, which are defined as errors based on L1 structures (for example, the house of my friend rather than my friend's house in Brazilian Portuguese (BP) speakers learning English); and

structural alterations, which include hypercorrections (for example, a BP speaker learning English will be aware of the need to avoid pronouncing word initial $\langle r\rangle$ as $[x]$ instead of $[I]$ and may 
over-correct word initial <h> to [I], giving [soutcl] for hotel-present author's data).

Misinterpretation can include an inability to discriminate distinctive phonemes in the TL, leading the learner to produce an inappropriate sound in particular contexts (an English speaker learning Brazilian Portuguese may produce the same vowel sound for the final vowels in $a v o ́$ and $a v \hat{o}$, for example, because of a perceptual inability to discriminate between the two phonemes).

Differing lengths of acquisition is a way of seeing the cumulative effects of cross-linguistic influence on the ability to achieve 'a high degree of mastery of a language' (Odlin 1989:38). Some languages may take longer to learn than others (because of relative degrees of difficulty at the L1-L2 interface), although empirical evidence for this is wholly lacking.

\section{Phonetics, phonology and transference Phonetics}

The phonetics of a given language has to do with physical characteristics of the sound production of that language, or the acoustics (Odlin, 1989:112). Sounds which seem identical between two languages may nevertheless be produced in different ways, such as with different pitch contours or with the mouth in a more or less open position. What often happens during acquisition is that the learner develops a 'compromise' form, or an approximation to the target sound that is neither fully like the L2 nor very similar to the L1 sound on which it may be based. Such compromises are influenced by the L1 norms but also reflect learner judgements of what L2 sounds are like.

\section{Phonology}

As we saw with Flege's (1986) notion of 'equivalence classification', this recognition of phonetic similarity affects the process of making interlingual identifications. However, these judgements of equivalence are based on more than acoustic perceptions. Where sounds are seemingly cognate, learners may see correspondences where none exist, especially if the orthographic cues support the identification.

But a further factor involved is the phonemic system of the TL. Studies have shown that non-native speakers will base their version of the $\mathrm{L} 2$ phonemes 
on the phonemes that make up the inventory for their L1. English speakers will distinguish between the /ii/ and /// phonemes while speakers of Brazilian Portuguese learning English tend not to, at least at early stages in acquisition. This can lead to hypercorrection.

\section{Segmental level effects}

At the level of single sounds, one classification (Moulton, 1962) sees four basic types of errors that may be traced to transfer effects: phonemic errors, phonetic errors, allophonic errors and distributional errors (Odlin, 1989:116). Phonemic errors include, for example, the speaker of Brazilian Portuguese producing [z] for English $/ \mathrm{\partial} /$ or [s] for $/ \theta /$ because of the absence of these lingua-dental fricatives in Brazilian Portuguese (present author's data).

Phonetic errors occur where there is cross-linguistic equivalence at the phonemic but not the phonetic level. The Brazilian Portuguese velar fricative $/ \mathrm{x} /$ does not exist in English outside Scotland, although $/ \mathrm{h} /$ does. It is expected that learners of either of these language will produce the sounds with different acoustic characteristics depending on their $\mathrm{L}$.

Allophonic errors are exemplified by the English speaker learning Brazilian Portuguese who aspirates word initial $/ t$, producing $\left[\mathrm{t}^{\mathrm{h}}\right]$.

Distributional errors are similar to allophonic errors, but are the result of the position in the word of the phoneme. Speakers of Brazilian Portuguese have no difficulty with pronouncing the $<$ sp $>$ cluster in word medial positions but will tend to augment the cluster with an epenthetic vowel in word initial position (giving [Ispo:tt] for sport).

\section{Suprasegmental effects}

At the level of word, phrase and sentence, cross-linguistic influences can be seen in the areas of stress, tone, rhythm and intonation. Stress patterns have a key role in comprehension, as Benrabah's (1994) study showed: when native listeners (of English) were presented with the learner pronunciation norMALLy they claimed to have heard "no money"; when the learner pronunciation was cheMISTry they interpreted this as "community". The source for this kind of stress placement error may or may not be the L1, but an analysis of the stress pattern system of the $\mathrm{L} 1$ and its relation to the $\mathrm{L} 2$ will reveal possible sources for this kind of transfer. 
Similarity at a suprasegmental level may have a facilitative role in acquisition. Odlin cites a study of Japanese, Finnish and German speakers learning English. German and Japanese have similar ways of using rising intonation for yes-no questions which is not shared in Finnish. KellerCohen's (1979) study demonstrated slower acquisition rates for this feature in Finnish speakers. Odlin states that it is sentence level characteristics such as rhythm and pitch that contribute most to the perception of a "foreign accent" in non-native speakers of L2s.

\section{Pronunciation universals}

Some phonological features are more common than others. The vowels $/ \mathrm{i} /, \mathrm{l} / \mathrm{and} / \mathrm{a} /$ occur in a majority of languages in the Maddieson (1984) survey, whereas $/ \mathrm{h} /$ (from Kurdish, for example) occurs in only 12. In terms of consonants, the same survey shows that $/ \mathrm{m} /$ and $/ \mathrm{b} /$ are more common (200-300 languages), while $/ x /$ and $/ \mathrm{ts} /$ occur in fewer than 80 . There is, claims Odlin, 'a rough correlation between the frequency of a sound and its difficulty for adults learning a second language' (Odlin 1989:120).

\section{Transfer and developmental factors}

A fundamental task in transfer studies is that of distinguishing transfer features and developmental features. Transfer features are the consequence of cross-linguistic influence and developmental features include those aspects of language acquisition that are visible in the development of a said language by its native speakers. A common feature in many languages is word final consonant devoicing and this is also found in children during first language acquisition. The difference in effect may depend on the kind of feature involved. Odlin cites evidence that in one example of learning English as a second language, developmental errors were common with fricatives and transfer errors affected other types of consonants. That is, the learner demonstrated the same kinds of errors with fricatives as native speakers of English while her other consonants were affected by her L1. As we saw above, Major's (1987) article argued that transfer errors belong to the earlier phase of acquisition and developmental errors to the later. 
Spelling

The influence of the orthography of the target language on its pronunciation is not straightforward. The learners involved may or may not be literate in their own language; that language may or may not use a similar writing system to the L2; the writing systems themselves may be a mixture, in the L1 - L2 interaction, of alphabetic, syllabic, or ideographic. A similarity in writing systems (as between Brazilian Portuguese and English) is a clear advantage for the literate learner. However, similarity may itself be the cause of problems, as when English has cognates in Portuguese which cause confusion, leading to the spelling *confort for comfort because the cognate form has $n$ in the place of the English $m$. Some English spellings may carry over into the TL, as when an early stage learner of Brazilian Portuguese produce * britânnico for britânico because the English form takes <-nn->. On the whole, though, and taking a good spelling system as being one that reflects closely the grapheme-phoneme correspondences in consistent ways, a language with a more 'phonetic' orthographic system will be easier to learn and language whose orthography causes problems for its native speakers (such as Chinese ideographs) will likely cause problems for learners of the language as an $\mathrm{L} 2$.

\section{Interlanguage phonology: principle theoretical concerms}

As we have seen, for a period, the notion of interlanguage was associated with the Contrastive Analysis Hypothesis (CAH), which simply stated suggested that by comparing the $\mathrm{L} 1$ and the target language (TL) it would be possible to identify (or predict) which aspects of the TL a learner (speaker of a specific L1) would have difficulty with. When the CAH proved less than efficient for a number of reasons (see Dulay and Burt, 1974; Ellis, 1994:306-9), people lost interest in the process of comparing languages to see what the - as it were - working relationship between them might be during acquisition. Currently, various models have replaced the simpler version of the $\mathrm{CAH}$ and interest has been re-awakened in that $\mathrm{L}, 1-\mathrm{L} 2$ relationship.

In addition, of course, other factors have required attention and these factors are relevant to language learning in general as well as to the development of phonological skills (Major, 1994). The whole notion of 'interlanguage' has re-emerged as a useful way of looking at the different stages of competence that learners demonstrate and interlanguage phonology 
studies have fitted in with this renewed interest, although it is clear that phonological skills are different in fundamental ways from the skills of morphosyntactic and semantic control, as we shall see throughout this discussion.

Age

The first place where this difference between phonological and other skills acquisition can be seen is in terms of the effect of age at initial stages of acquisition. It is clear that language learning can be highly successful in terms of syntax and semantics (where 'successful' means something like 'native-like competence' or, in Jenkins' (2000) terminology, the level of Bilingual English Speaker, or BES) but rather less so in the area of phonology. This 'Joseph Conrad' phenomenon is well attested: Conrad was born of Polish parents and apparently retained a fearsome Polish accent all his life; he also wrote some of the great works of fiction in English of the $20^{\text {th }}$ century. Of course, other socio-psychological factors may be involved which are masked by the fact of the learner's age, such as not wishing to integrate completely with the TL community, or preserving an accent that may carry perceived intellectual status (the 'Kissinger' phenomenon). In any event, there's not much a classroom teacher can do about this factor: her learners are the age they are and started learning at the age they started learning.

\section{Personality}

Where the teacher can be influential is with personality variables. These do not affect the underlying linguistic nature of the interlanguage, but they do affect the rate at which a language is learned and the ultimate level of attainment. Variables included here are those of self-esteem, risk-taking, anxiety, empathy, extroversion and motivation, although even this last can be inhibited by other factors (Major, 1994). Another variable that has been researched is musicality, although, counter-intuitively, no correlation has been found between musicality and control over prosodic features (such as intonation).

The early CAH attributed all 'non-native deviations' as 'interference' from the $\mathrm{L} 1$ and claimed a predictive ability (i.e. that it could foresee where the problems in $\mathrm{L} 2$ acquisition would arise). The weaker version of the $\mathrm{CAH}$ was post facto analytical, explaining what had gone wrong. In neither version was it able to explain why only some Japanese learners of English have $/, \mathrm{r} /$ 
problems, for example. A refined version of the hypothesis was based on 'phonological similarity', sometimes known as 'interlingual identifications' or 'equivalence classifications' (see Flege, 1986). This basically stated that where two languages had elements in common, this would have a facilitating effect. So if there were a grammatical structure in the $\mathrm{L} 1$ with a counterpart in the TL, this structure would be acquired more easily and earlier than structures that were very unalike.

Once again, though, for phonology this process seems to operate in a contrary fashion: where two phonological elements are seen by the learner as nearly the same, she will settle for the L1-based version of the target phoneme, rather than create a new phonemic category for that sound. The more unlike the phonemes of the TL are from the L1, the more easily they seem to be acquired, as the previously established phonemic categories of the $\mathrm{Ll}$ are not called in to operation.

\section{Markedness}

An advance on contrastive analysis was offered in theories of markedness which promoted the view that the more 'marked' an aspect of the TL or the L1 was, the more difficult it would be to gain control over. By 'marked' was meant something like relative degree of frequency and/or simplicity: if a specific feature of the language was very common, it was seen as 'unmarked', and vice versa; if a feature depended on another feature (where, for example, pro-drop languages imply verb inflection), it was regarded as more 'marked'. So the markedness differential hypothesis (MDH) (Eckman, 1977) said that the more marked the differences between the L1 and the TL, the greater the difficulty there would be for acquisition. If there were no such differences, the hypothesis made no prediction.

An advance on the MDH that did offer to predict L2 acquisition processes was the structural conformity hypothesis $(\mathrm{SCH})$, which claimed that where there was no great difference in terms of markedness, then language universals would operate and learners would show evidence of this in their production errors. So even languages that show a preference for closed syllables (the minority), a tendency in acquisition would for the learner to demonstrate an open syllable production ( $\mathrm{CV}$ rather than $\mathrm{CVC}$ ), producing schwa paragoge, for example (adding a vowel at the end of a syllable ending in a consonant at the end of a word). 
Linked to the structural conformity hypothesis is the whole question of universal development factors. These are processes that take place during the acquisition of the L1 (First Language Acquisition - FLA) and recur during Second Language Acquisition (SLA). The argument is that transfer can only occur when there are corresponding structures in the L1 and the L2; otherwise developmental processes operate. For speakers of L1 English, acquiring clicks in Bantu would present the same problems as for native speakers of Bantu, as clicks are not phonemically part of English (though they are phonetically available) (Major, 1994); when the same learners are learning French, there is a tendency for French dental stops to be substituted with English (i.e. L1-derived) alveolar stops. The first process is developmental; the latter is evidence of transfer.

\section{Style}

It is important not to forget the simpler elements of language learning and the question of style, while not complex, may nevertheless be significant for SLA. In general terms, when learners are operating in more formal styles, the target-like quality of their production improves. This may simply be because they are paying more attention to their production ('monitoring' in Krashen's (1981) sense). There is also the phenomenon of interlocutor accommodation, seen when Chinese-Thai bilinguals sound more Thai-like when talking to Thai speakers and more Chinese when talking to Chinese speakers. Indeed, the whole question of accommodation is seen by proponents of TELL as fundamental to non-native speakers exchanges in English. Sex is also involved here: female learners will use prestige variants more frequently than males will, and a group of Cambodian men were seen to identify the pronunciation of final -ing as [In] with male L1 speakers of English, and therefore of greater prestige, which they then proceeded to use in formal contexts.

In FLA, we can see another distinction between phonological and other language skills. The child language learner learning her L1 will, at the morpho-syntactic level, have a target production in mind that may be unlike adult speech: Daddy go work is precisely the intended production because it represents the intermediate stage of the grammar at the moment of speaking; when the child produces [fis] for fish, however, the production is not matched to the underlying representation (UR), which may well be/fif/ but which the child cannot physiologically perform. The phonological intention does not 
always lead to adult-like phonological output. In the case of SLA, a nonnative target (or UR) will always produce non-native output; but a native UR will not necessarily produce native output: the speaker knows what to do but cannot manage it.

\section{Questions of transfer}

If the major process in SLA at the phonological level is transfer, we need to be sure about what this concept may involve. A basic definition of transfer is that it represents the use of $\mathrm{L} 1\left(\mathrm{~L}_{n}\right)$ knowledge in some way during the acquisition of $\mathrm{L} 2$. This use is evidenced in divergent $T L$ forms, avoidance strategies and the over-production of certain TL elements, among others. One question to be decided is if transfer operates in the same manner if the learning is in contexts of formal instruction (i.e. classrooms) and in informal situations (people living in the TL community but not officially 'studying' the language).

Other unresolved questions relating to transfer include the basic one of what is it that is transferred? Is it rules, strategies, linguistic elements? And how is this affected by prior knowledge of more than one language? This last question seeks to know if the previous acquisition of other L2s has any effect (and if so what kind) on the subsequent acquisition of other languages. This relates to the question of the relative availability of Universal Grammar during SLA and also raises the possibility that transfer can be bidirectional: the facilitation hypothesis (see 'phonological similarity') suggests that learning of the TL can have a return effect on the L1 (French L1 speakers learning English have been noted to change their phonetic production of some phonemes in the direction of a more 'English-like' quality).

The interaction of transfer and the intermediate state of the interlanguage has led to a discussion of the 'cessation' of learning as evidenced by the failure to acquire an $\mathrm{L} 2$ feature: is this a matter of reaching a 'plateau' of interlanguage competence which is difficult to pass beyond, or does it signify a 'stabilization' at that level, otherwise known as fossilization? (Selinker, 1972, 1992).

\section{Interlanguage phomology and language transfer}

To come to the heart of the matter, we should look at what actual processes are involved at the phonological and phonetic level in terms of 
transfer of knowledge and categories between the L1 and the TL. The following is summarised from Odlin (1989).

These processes can be phonetic or phonemic. Phonetically, it may be that a main difference between L1 and L2 forms is contained in the articulatory positions of the vocal apparatus - the lips more rounded, the tongue further advanced; or in the length of the voice onset time (VOT), or in consonant length (Arabic/d/is longer in word final position than American English / $d$ /tends to be, so Arabic L1 speakers learning English will produce longer word final [d:]).

Phonemically, we are dealing with the whole question of interlingual identification, or equivalence classification according to Flege's (1986) model. Phonemic differences may in fact override phonetic considerations: Spanish has the phonemes $/ \mathrm{n}, \mathrm{y} /$ but they are not phonemically contrasted, as in English fan and fang, which Spanish L1 speakers have problems with differentiating. Again, perceptive skills may be more efficient than productive skills: Korean learners have been shown to be more than capable of distinguishing aurally between $/ \mathrm{V} /$ and $/ \mathrm{r} /$.

Segmental errors occur when cross-linguistic differences lead to divergent production. This can operate at 4 levels: phonemically, German $/ \mathrm{x}$, $\mathrm{k} /$ are difficult for L1 English speakers; phonetically German uvular/s/ is physiologically complex; allophonic $[r]$ in American English cannot be transferred to intervocalic < $>$ in German (to produce *[bira] for Bitte); and distributionally speaking, English L1 speakers seem to have no problem with word final /ts/ in German (Sitz) but find it complicated in word initial positions $(z u)$ and in word medial position (giving the common pronunciation of et cetera as [Ek'setra] rather than the standard /et'setrə/).

Prosodically, errors in stress seem to be the most likely cause of unintelligibility. This was clear from Benrabah's (1994) study (see page 21 "norMALly" heard as "no money"; "airPORT" as "approached"). Similarly, cognate forms in the L1 and L2 may cause production errors: the French and English words moteur and motor are superficially similar but the stress placement on the inappropriate syllable may cause confusion.

Cross-linguistic frequency of certain phonemes is a factor in the process of transfer between languages. As the Maddieson (1984) survey (see page 21 above) showed, some sounds are more common in the world's languages than others and the suspicion is that less frequent sounds (globally speaking) are more difficult to acquire. 
There also seem to be common phonological rules for languages, socalled natural rules. Word final obstruent de-voicing is one of these, although it is not part of English. The frequency of the rule predicts the relative ease with which it is learned. Despite its absence from English, EnglishL1 speakers learning German acquire the rule early, whereas German L1 speakers learning English have difficulty in suppressing the rule and therefore have problems distinguishing between nod and not.

All these factors may be involved at some stage during the development of a learner's interlanguage phonology, either separately or concurrently (and some factors may be causal, bringing others into play). These are the elements that motivate the basic research questions in this area.

\section{Conclusion}

As was suggested in the introduction, current research interests in the area of interlanguage phonology are focused on a number of themes:

- the descriptive detail of specific target languages in particular L1-L2 interfaces (Keys 1999b; forthcoming (c));

- the contribution of various forms of phonological theory to the understanding of the development of a second language phonology (i.e. generative phonology (Chomsky \& Halle 1968), autosegmental phonology (Goldsmith 1990), CV phonology (Clements \& Keyser 1983), and Optimality Theory (Prince \& Smolensky 1993);

- the question of developing phonological systems and their interaction in L2-L2 encounters in terms of parameters of intelligibility (Jenkins 2000);

- the influence of orthography on Underlying Representations and oral production.

Studies in SLA are capable of making contributions to linguistic theory at a more abstract level; moreover, theory in applied linguistics must also begin to recognise and give value to data and evidence that is particular to

\footnotetext{
${ }^{3}$ For an overview of these theories, see also Goldsmith (1999) and Cristófaro Silva (1998).
} 
the endeavours encapsulated in the term 'applied linguistics' itself. As Widdowson (2000) noted,

linguistics over recent years has extended its theoretical and descriptive scope to account for aspects of E-language. The discipline has thus extended the range of data which it seeks to deal with, but although this will necessarily involve the development of new concepts and procedures, these will still conform to some set of abstract principles which define the specialist discourse of linguistic enquiry and constitute the criteria for its validity. (Widdowson, 2000:24)

The articulation between phonological theory analysis of data such as the oral production of L2 phonologies and the identification of the factors at work in determining the nature of that production (for example) with a socio-cultural awareness of the reality of linguistic exchanges in real life (in TEIL) offers a rich and diverse body of theoretical and practical analysis and description that will be capable of raising the appropriate questions to be addressed by applied linguistics.

\section{References}

ADJEMIAN, C. On the nature of interlanguage systems. Language Learning, v. 26, p. 297-320, 1976.

ANDERSON, R. (Ed.). The acquisition and use of Spanish and English as first and second languages. Washington: TESOL, 1979.

BACKMAN, N. Intonation problems of eight Spanish-speaking adults learning English. 1977. Tese (Doutorado), Boston University.

BENRABAH, M. Word-stress - a source of unintelligibility in English, International Review of Applied Linguistics, v.35, n.3, p. 145-65, 1997.

BENSON, B. Universal Preference for the Open Syllable as an Independent Process in Interlanguage Phonology. Language Learning , v.38, n.2, p. 22142, 1988.

BRIERE, E. An investigation of phonological interference. Language, v. 42, p. 768-796, 1966.

BROWN, H., YORIO, C.; R.CRYMES, R.. On TESOL '77. Washington: TESOL. 1977.

BONGAERTS, T.; VAN SUMMEREN, C.; PLANKEN, B.; SCHILS, E. Age and Ultimate Attainment in the Prounciation of a Foreign Language. 
Studies in Second Language Acquisition, v.19, p. 447-65, 1997.

CELCE-MURCIA, M. Phonological factors in vocabulary acquisition: a case study of a two-year-old English-French bilingual. Working Papers in Bilingualism, v.13, p. 27-41, 1977.

CLEMENTS, G. N.; KEYSER, S. CV phonology: a generative theory of syllable. Cambridge: The MIT Press, 1983.

CORDER, S. P. The significance of learners' errors. International Review of Applied Linguistic, v.5, n.4, p. 161-170, 1967.

CORDER, S. P. The role of the mother tongue. In: GASS \& SELINKER (Eds.) Language Transfer in Language Learning. Amsterdam: John Benjamins 1983/1994.

CRISTÓFARO SILVA, T. Fonética e Fonologia do Português: roteiro de estudos e guia de exercícios. São Paulo: Contexto, 1998.

CRYSTAL, D. Global English. Cambridge University Press, 1998.

CRYSTAL, D.; CRYSTAL, H. Words on Words. Harmondsworth: Penguin, 2000.

DICKERSON, L. Internal and external patterning of phonological variability in the speech of Japanese learners of English. 1974. Tese (Doutorado), University of nlinois.

DICKERSON, W. Language variation in applied linguistics. International Review of Applied Linguistics, v.35, p. 120-41, 1977.

DULAY, H.; BURT, M. Natural sequences in child second language acquisition. TESOL Quarterly, v.8, p. 37-53, 1974.

ECKMAN, F. R. Markedness and the contrastive analysis hypothesis. Language Learning, v.27, p.315-330, 1977.

ELLIS, R. The Study of Second Language Acquisition. Oxford: Oxford University Press, 1994.

ERVIN-TRIPP, S. M. Is second language learning like the first? TESOL Quarterly, v.8, n.2, p. 111-127, 1974.

FLEGE, J. E. Effects of Equivalence Classification on the Production of Foreign Language Speech Sounds. In: JAMES, A \& LEATHER, J (Eds.) Sound Patterns in Second Language Acquisition. Dordrecht, Holland: Foris 1986.

FRIES, C. C. Teaching and Learning English as a Foreign Language. University of Michigan Press, 1945.

GASS, S.; SELINKER, L. (Eds.) Language Transfer in Language Leaming. Amsterdam: John Benjamins 1983/1994.

GOLDSMITH, J. A. An Overview of Autosegmental Phonology. In: 
GOLDSMITH (Ed.) Phonological Theory: the essential readings. Oxford: Blackwell Publishers, 1999.

GOLDSMITH, J. A. (Ed.) Phonological Theory: the essential readings. Oxford: Blackwell Publishers, 1999.

HILL, J. Foreign accents, language acquisition and cerebral dominance revisited, Language Learning,20, p. 237-48, 1970.

HOLLIDAY, A. Appropriate Methodology and Social Context. Cambridge: Cambridge University Press, 1994.

IOUP, G.; WEINBERGER, S. H. (Ed.) Interlanguage Phonology: the acquisition of a second language sound system. Rowley: Newbury House, 1987.

JAMES, A.; LEATHER, J. Sound Patterns in Second Language Acquisition. Dordrecht, Holland: Foris, 1986.

JENKINS, J. The Phonology of English as an International Language. Oxford: Oxford University Press, 2000.

KELLER-COHEN, D. Systematicity and variation in the non-native child's acquisition of conversational skills. Language Learning, v.29,p. 27-44, 1979. KEYS, K. J. Current trends in pronunciation teaching. IATEFL Issues, v.151, p. 6-7, Whitstable, Kent, UK: IATEFL, 1999a.

KEYS, K. J. Making the right noises: pronunciation and teacher training in Brazil. Speak Out!, n. 24, p. 33-40. Whitstable: IATEFL 1999 b.

KEYS, K. J. Teaching Pronunciation for English as an International Language. Speak Out!, issue 26:38-43. Whitstable: IATEFL 2000a.

KEYS, K. J. Discourse Phonology in the Language Curriculum: a review of current thinking in teaching pronunciation in EFL courses. Linguagem $e$ Ensino, Pelotas: UCPel, v.3, n.1, p. 89-105, 2000b.

$\mathrm{KEYS}, \mathrm{K}$. J. Interlanguage phonology: theoretical questions and empirical data. Speak Out! issue 27, p. 20-26. Whitstable: IATEFL, 2001.

$\mathrm{KEYS}, \mathrm{K}$. J. Interlanguage phonology: theoretical questions and empirical data. Linguagem e Ensino, Pelotas: UCPel . No prelo (a).

KEYS, K. J. First language influence on spoken English of Brazilian students of EFL: preliminary results of a longitudinal study. English Language Teaching Journal, v.56, n.1, Oxford: Oxford University Press. No prelo (b).

KRASHEN, S. Second Language Acquisition and Second Language Learning. London: Pergamon Press, 1981.

KRASHEN, S. The Input Hypothesis: Issues and Implications. London: Longman, 1985. 
LADO, R. Linguistics across Cultures: Applied Linguistics for Language Teachers. Ann Arbor: University of Michigan, 1957.

LADEFOGED, P.; MADDIESON, I. The Sounds of the World's Languages. London: Blackwell, 1996.

MACARTHUR, T. The English Languages. Cambridge: Cambridge University Press 1999.

MADDIESON, I. Patterns of Sounds. Cambridge: Cambridge University Press, 1984.

MAJOR, R.C. A model for interlanguage phonology. In: IOUP, G.; WEINBERGER, S. H. (Ed.). Interlanguage Phonology. Rowley: Newbury House, 1987. p. 101-124.

MAJOR, R.C. Current trends in Interlanguage Phonology. In: YAVAS, M. First and Second Language Phonology. San Diego: Singular Publishing Group Ltd., p. 23-51, 1994.

MOULTON, W. Toward a classification of pronunciation errors. Modem Language Journal,46, p. 54-71, 1962.

NEMSER, W. Approximative systems of foreign language learners. International Review of Applied Linguistics,9, p. 115-124, 1971.

ODLIN, T. Language Transfer: cross-linguistic influence in language learning. Cambridge: Cambridge University Press, 1989.

OLLER, D. K. Toward a general theory of phonological processes in first and second language learning. In: WESTERN CONFERENCE ON LINGUISTICS, 1974, Seattle.

PENNYCOOK, A. English and the Discourses of Colonialism. London \& New York: Routledge, 1998.

PRINCE, A. \& P.SMOLENSKY. Optimality Theory: constraint interaction in generative grammar. Cambridge: The MIT Press, 1993.

SCHACHTER, J. Interrelationships between total production and error production in the syntax of adult learners. Papers in ESL, NAFSA, 1978.

SCHACHTER, J.; CELCE-MURCIA, M. Some reservations concerning error analysis. TESOL Quarterly, v. 11, 1977.

SCHUMANN, J. The acquisition of English negation by speakers of Spanish: a review of the literature. In: R.ANDERSON (Ed.). The acquisition and use of Spanish and English as first and second languages, 1979, p.3-32.

SELINKER, L. Interlanguage. International Review of Applied Linguistics, 10, p. 209-231, 1972.

SELINKER, L. Rediscovering Interlanguage. London: Longman, 1992.

TARONE, E. Interlanguage as chameleon. Language Learning, 29, p. 181191, 1979. 
TARONE, E.. The Phonology of Interlanguage. In: IOUP, G.; In: WEINBERGER, S. (Ed.) 1987, p. 70-85.

VALDMAN, A. Pidgin and Creole Linguistics. Bloomington: Indiana University Press, 1977.

WHITE, L. Universal Grammar and Second Language Acquisition. Amsterdam: John Benjamins 1989.

WIDDOWSON, H.G. On the limitations of linguistics applied. Applied Linguistics, v. 21, n. 1, p. 2-25, 2000.

YAVAS, M. First and Second Language Phonology. San Diego: Singular Publishing Group Ltd., 1994.

ZOBL, H. Developmental and transfer errors: their common bases and (possibly) differential effects on learning. TESOL Quarterly, v. 14, n. 4, p. 469-79, 1980. 